Original Article

\title{
The Diversity of Monocotyledone Plants in Pu Hoat Nature Reserve, Nghe An Province
}

\author{
Nguyen Danh Hung ${ }^{1}$, Tran Minh $\mathrm{Hoi}^{2}$, Nguyen Thi Hoai Thuong ${ }^{3}$, Do Ngoc Dai ${ }^{4}$ * \\ ${ }^{1}$ Graduate University of Science and Technology, Vietnam Academy of Science and Technology, \\ 18 Hoang Quoc Viet, Cau Giay, Hanoi, Vietnam \\ ${ }^{2}$ Institutes of Ecology and Biological Resources, Vietnam Academy of Science and Technology, \\ 18 Hoang Quoc Viet, Cau Giay, Hanoi, Vietnam \\ ${ }^{3}$ School of Natural Science Education, Vinh University, 182 Le Duan, Vinh, Nghe An, Vietnam \\ ${ }^{4}$ Faculty of Agriculture, Forestry and Fishery, Nghe An College of Economics, Nghe An, \\ 51 Ly Tu Trong, Ha Huy Tap, Vinh, Nghe An, Vietnam
}

Received 12 December 2018

Revised 10 March 2019; Accepted 16 March 2019

\begin{abstract}
The Monocotyledone in Pu Hoat Nature Reserve (Nghe An province) was surveyed and 432 species of 173 genera and 37 families were identified, adding 260 species, 76 genera and 8 families to the $2013 \mathrm{Pu}$ Hoat plant list. There are 22 Monocotyledone species on Pu Hoat plant list reported threatened and listed in the Red Data Book of Vietnam (2007). The useful plant species of the Pu Hoat Monocotyledone are categorized as follows: 197 species as medicinal plants, 48 species for food and food stuffs, 94 species for ornament, and 38 species for essential oil. The Monocotyledone species in Pu Hoat Nature Reserve are comprised mainly of tropical elements, accounting for $64.36 \%$, of which, the endemic elements with $23.38 \%$; temperate elements, $6.90 \%$; cultivated elements, $3.24 \%$; unknown elements, $1.85 \%$; and global elements, $0.18 \%$. The Spectrum of Biology (SB) of the flora in Pu Hoat Nature Reserve is summarized as follows: $\mathrm{SB}=41.90 \mathrm{Ph}+24.77 \mathrm{Ch}+8.33 \mathrm{Hm}+15.28 \mathrm{Cr}+8.56 \mathrm{Th}+1.16 \mathrm{Hy}$.
\end{abstract}

Keywords: Diversity, Monocotyledone, Pu Hoat, Nature, Plants, Nghe An.

\footnotetext{
${ }^{*}$ Corresponding author.

Email address: daidn23@gmail.com

https://doi.org/10.25073/2588-1140/vnunst.4843
} 


\title{
VNU Journal of Science: Natural Sciences and Technology
} Journal homepage: https://js.vnu.edu.vn/NST

\section{Đa dạng thực vật lớp Một lá mầm (Monocotyledone) ở Khu Bảo tồn Thiên nhiên Pù Hoạt, tỉnh Nghệ An}

\author{
Nguyễn Danh Hùng ${ }^{1}$, Trần Minh Hợi ${ }^{2}$, Nguyễn Thị Hoài Thương ${ }^{3}$, Đỗ Ngọc Đài ${ }^{4}$,* \\ ${ }^{1}$ Hoc Viện Khoa học và Công Nghệ, Viện Hàn lâm Khoa học và Công nghệ Việt Nam, \\ 18 Hoàng Quốc Việt, Cầu Giấy, Hà Nội, Việt Nam \\ ${ }^{2}$ Viện Sinh thái và Tài nguyên Sinh vật, Viện Hàn lâm Khoa họ và Công nghệ Việt Nam, \\ 18 Hoàng Quốc Việt, Cầu Giấy, Hà Nọii, Việt Nam \\ ${ }^{3}$ Viện Su phạm Tự nhiên, Truòng Đại học Vinh, 182 Lê Duẩn, Vinh, Nghệ An, Việt Nam \\ ${ }^{4}$ Khoa Nông Lâm Ngu, Trưòng Đại hoc Kinh tế Nghệ An, \\ 51 Lý Tự Trọng, Hà Huy Tập, Vinh, Nghệ An, Việt Nam \\ Nhận ngày 12 tháng 12 năm 2018 \\ Chỉnh sửa ngày 10 tháng 03 năm 2019; Chấp nhận đăng ngày 16 tháng 03 năm 2019
}

Tóm tắt: Kết quả điều tra thực vật lớp Một lá mầm ở Khu Bảo tồn Thiên nhiên (BTTN) Pù Hoạt, tỉnh Nghệ An đã xác định được 432 loài, 173 chi và 37 họ; bổ sung 8 họ, 76 chi và 260 loài cho danh lục Pù Hoạt (2013). Lớp Một lá mầm Pù Hoạt có 22 loài có nguy co bị tuyệt chủng được ghi trong Sách Đỏ Việt Nam (2007) với 2 loài rất nguy cấp (CR), 6 loài nguy cấp $(\mathrm{EN}), 13$ loài sẽ nguy cấp (VU) và 1 loài ít nguy cấp (LR). Giá trị sử dụng của lớp Một lá mầm ở Pù Hoạt với cây làm thuốc có số loài cao nhất 197 loài, cây làm cảnh 94 loài, cây ăn được 48 loài, cây cho tinh dầu 38 loài, cây cho thức ăn gia súc 35 loài, cây cho gia vị và cây đan lát cùng 12 loài, cây lấy gỗ 9 loài và cây cho sợi 8 loài. Về yếu tố địa lý cao nhất là yếu tố nhiệt đới chiếm $64,36 \%$, yếu tố đặc hữu và cận đặc hữu đứng thứ 2 chiếm $23,38 \%$, yếu tố ôn đới chiếm $6,90 \%$; yếu tố cây trồng $3,24 \%$; yếu tố chưa xác định chiếm $1,85 \%$ và yếu tố toàn cầu $0,18 \%$. Qua quá trình nghiên cứu đã lập phổ dạng sống của Lớp Một là mầm: $\mathrm{SB}=41,90 \mathrm{Ph}+24,77 \mathrm{Ch}+8,33 \mathrm{Hm}+15,28 \mathrm{Cr}+$ $8,56 \mathrm{Th}+1,16 \mathrm{Hy}$.

Tù khóa: Đa dạng, Lớp Một lá mầm, Nghệ An, Pù Hoạt, Thực vật, Yếu tố địa lý.

\section{1. Đặt vấn đề}

Khu Bảo tồn Thiên nhiên Pù Hoạt có tổng diện tích tự nhiên 85.761 ha, trong đó rừng đặc

\footnotetext{
*Tác giả liên hệ.

Địa chi email: daidn23@gmail.com

https://doi.org/10.25073/2588-1140/vnunst.4843
}

dụng 34.589 ha. Nằm trên địa bàn 9 xã thuộc huyện Quế Phong: Tri Lễ, Tiền Phong, Thông Thụ, Hạnh Dịch, Nậm Giải, Đồng Văn, Nậm Nhoóng, Cắm Muộn và xã Châu Thôn. Có tọa độ địa lý từ 19²7'46" đến 1959'55" vĩ độ Bắc; 104³7'46” đến $105^{\circ} 11^{\prime} 11^{\prime}$ kinh độ Đông. Khí hậu ở Pù Hoạt thể hiện tính chất mùa rõ rệt. 
Mùa khô từ tháng 12 năm trước đến tháng 4 năm sau. Nhiệt độ ở trong khoảng 14,9 $38,4^{\circ} \mathrm{C}$, thường có sương giá, tập trung vào tháng 01 và tháng 02 . Độ ẩm trong thời gian mùa khô thấp, vào tháng 3 tháng 4 độ ẩm thường $82,0-83,0 \%$, cá biệt có năm là $11,0 \%$. Lượng mưa trong mùa này không đáng kể. Gió chủ yếu theo hướng Đông-Bắc. Mùa mưa từ tháng 5 đến tháng 11 [1]. Hiện nay, đã có một số công trình nghiên cứu về đa dạng thực vật ở Pù Hoạt của Lê Thị Hương và cs [2], Hoàng Danh Trung và cs [3], Sở Khoa học và Công nghệ Nghệ An [4]. Tuy nhiên, nghiên cứu chuyên sâu về lớp Một lá mầm ở Pù Hoạt thì chưa được đề cập đến. Bài báo này nhằm đánh giá tính đa dạng Lớp Một lá mầm ở Khu Bảo tồn Thiên nhiên Pù Hoạt làm cơ sở khoa học cho công tác bảo tồn.

\section{Vật liệu và phương pháp nghiên cứu}

\subsection{Vật liệu}

Đối tượng là các loài thực vật thuộc lớp Một lá mầm ở Khu BTTN Pù Hoạt, Nghệ An; tổng số mẫu thu được là hơn 1.200 tiêu bản được lưu trữ tại Phòng mẫu thực vật, Khoa Nông Lâm Ngư, Trường Đại học Kinh tế Nghệ An và Ban quản lý Khu BTTN Pù Hoạt.

\subsection{Phuơng pháp nghiên cưu}

Thu mẫu và xử lí mẫu: Tiến hành thu mẫu theo phương pháp của Nguyễn Nghĩa Thìn [5]. Công việc được tiến hành từ tháng 02 năm 2017 đến tháng 12 năm 2017.

Định loại: Sử dụng phương pháp hình thái so sánh và dựa vào các tài liệu: Cẩm nang tra cứu và nhận biết các họ thực vật hạt kín ở Việt Nam của Nguyễn Tiến Bân (1997) [6], Cây cỏ Việt Nam của Phạm Hoàng Hộ (2000) [7]. Thực vật chí Trung Quốc [8]. Lập danh lục thực vật theo Brummitt (1992) [9]. Chỉnh lý tên khoa học dựa vào tài liệu: Danh lục các loài thực vật Việt Nam [10]. Đánh giá đa dạng yếu tố địa lý theo Nguyễn Nghĩa Thìn (2007) [5]. Đánh giá tính đa dạng về dạng sống theo Raunkiaer (1934) [11]. Đánh giá về giá trị sử dụng dựa vào phương pháp phỏng vấn có sự tham gia
(PRA) và các tài liệu của Võ Văn Chi (2012) [5], Triệu Văn Hùng và cs (2007) [7]. Đánh giá về nguồn gen quý hiếm theo: Sách Đỏ Việt Nam (2007) [12].

\section{Kết quả nghiên cứu và thảo luận}

\section{1. Đa dạng về thành phần loài}

Kết quả điều tra, thu thập mẫu thực vật của lớp Một lá mầm ở Khu BTTN Pù Hoạt, Nghệ An đã xác định được 432 loài, 173 chi và 37 họ. Trong đó, đã bổ sung 260 loài, 76 chi và 8 họ cho danh lục thực vật Khu BTTN Pù Hoạt (2013) [4] và bổ sung 01 loài mới cho hệ thực vật Việt Nam là Gừng nudicarpum (Zingiber nudicarpum) [13].

Để thấy được tính đa dạng thực vật lớp một lá Mầm ở Khu BTTN Pù Hoạt, kết quả được so sánh với Vườn Quốc gia Pù Mát (2017) [14] và Khu BTTN Xuân Liên (2016) [15], bảng 1.

\section{Bảng 1. So sánh lớp Một lá mầm ở Khu BTTN Pù} Hoạt với Xuân Liên và Pù Mát

\begin{tabular}{lllll}
\hline $\begin{array}{l}\text { VQG, } \\
\text { KBTTN }\end{array}$ & Số họ & Số chi & $\begin{array}{l}\text { Số } \\
\text { loài }\end{array}$ & $\begin{array}{l}\text { Diện tích } \\
\text { (ha) }\end{array}$ \\
\hline Pù Hoạt & 37 & 173 & 432 & 35.000 \\
Pù Mát [9] & 32 & 161 & 386 & 94.000 \\
$\begin{array}{l}\text { Xuân Liên } \\
\text { [13] }\end{array}$ & 24 & 125 & 273 & 26.300 \\
\hline
\end{tabular}

Như vậy, qua Bảng 1 cho thấy, tuy Pù Hoạt có diện tích nhỏ hơn rất nhiều so với Pù Mát (35.000 ha so với 94.000 ha) và cao hơn Xuân Liên (35.000 ha so với 26.300 ha), tuy nhiên có số họ, chi loài cao hơn hẳn $(37$ họ so với $\mathrm{Pù}$ Mát là 32 và Xuân Liên là 24), 173 chi so với 161 và 125 tương ứng với Pù Mát và Xuân Liên; 432 loài so với 386 và 273 của Pù Mát và Xuân Liên. Như vậy, tính đa dạng của lớp Một lá mầm ở Pù Hoạt là khá cao.

\section{2. Đa dạng về giá trị sử dụng}

Giá trị sử dụng của các loài thực vật Một lá mầm ở Khu BTTN Pù Hoạt được xác định bằng phương pháp điều tra trong nhân dân (PRA) và theo các tài liệu: Từ điển cây thuốc của Võ Văn 
Chi (2012) [16], Danh lục các loài thực vật Việt Nam Tập III của Nguyễ் Tiến Bân (Chủ biên) (2005) [10], Lâm sản ngoài gỗ [17]. Trong 432 loài thì có 283 loài cho giá trị sử dụng chiếm $65,51 \%$ tổng số loài (Bảng 2).

Bảng 2. Giá trị sử dụng của các loài thực vật ở Khu BTTN Pù Hoạt

\begin{tabular}{llcc}
\hline TT & Giá trị sử dụng & Số loài* & Tỉ lệ (\%) \\
\hline 1 & Làm thuốc (Thu) & 197 & 45,60 \\
2 & Cây làm cảnh (Can) & 94 & 21,76 \\
3 & Cây ăn được (And) & 48 & 11,11 \\
4 & Cây cho tinh dầu (Ctd) & 38 & 8,80 \\
5 & Cây làm thức ăn gia & 35 & 8,10 \\
& súc (Ags) & & \\
6 & Cây làm gia vị (Gvi) & 12 & 2,78 \\
7 & Cây cho đan lát (Dan) & 12 & 2,78 \\
8 & Cây cho gỗ (Go) & 9 & 2,08 \\
9 & Cây cho sợ (Soi) & 8 & 1,85 \\
\hline
\end{tabular}

*Một loài có thể cho 1 hoặc nhiều giá trị sử dụng khác nhau

Kết quả Bảng 2 cho thấy, giá trị sử dụng của các loài Một lá mầm ở Pù Hoạt thì cây làm thuốc có số loài cao nhất với 197 loài (chiếm $45,60 \%$ ) tổng số loài, chủ yếu ở các họ Gừng
(Zingiberaceae), Ráy (Araceae), Kim cang (Smilaceae), Bách bộ (Stemonaceae)...; cây làm cảnh với 94 loài chiếm $21,76 \%$ tổng số loài chủ yếu thuộc các họ Lan (Orchidaceae), Ráy (Araceae), Mạch môn (Convallariaceae)...; tiếp đến là nhóm cây ăn được với 48 loài (chiếm $11,11 \%$ ); nhóm cây cho tinh dầu với 38 loài chiếm $8,80 \%$; nhóm cây làm thức ăn gia súc với 35 loài chiếm $8,10 \%$; nhóm cây cho gia vị và đan lát cùng với 12 loài chiếm 2,78\%; nhóm cây cho gỗ và nhóm cây cho sợi với số loài tương ứng là 9 và 8 loài.

\subsection{Các loài thực vật quý hiếm}

Thực vật Một lá mầm ở Khu BTTN Pù Hoạt nói chung phải chịu nhiều sức ép do các hoạt động dân sinh như nạn phá rừng, chặt gỗ làm nguyên liệu sản xuất hoặc làm củi,...mà hậu quả của nó là diện tích rừng giảm đi nhanh chóng đi kèm với các nguy cơ sinh thái suy giảm. Cuối cùng làm cho số loài có nguy cơ bị tuyệt chủng ngày càng tăng. Theo "Sách Đỏ Việt Nam, 2007" đã thống kê được 22 loài (chiếm $7,00 \%$ tổng số loài thực vật nguy cấp, quý hiếm) thực vật một lá mầm trong khu hệ này đang bị đe dọa tuyệt chủng.

Bảng 3. Các loài thực vật Một lá mầm đang bị đe dọa ở Khu BTTN Pù Hoạt

\begin{tabular}{|c|c|c|c|c|}
\hline TT & Tên khoa học & Tên Việt Nam & Họ & $\begin{array}{l}\text { Mức độ } \\
\text { nguy cấp }\end{array}$ \\
\hline & $\begin{array}{l}\text { Acorus macrospadiceus (Yam.) F. N. Wei } \\
\text { \& Y. K. Li }\end{array}$ & Thủy xương bồ lá to & Acorceae & $\mathrm{EN}$ \\
\hline & Amorphophallus verticillatus Helt. & Nưa hoa vòng & Araceae & LR \\
\hline & Homalomena gigantea Engl. & Thiên niên kiện lá to & Araceae & VU \\
\hline & Homalomena piereana Engl.et K. Krause & Thần phục & Araceae & VU \\
\hline & Calamus platyacanthus Warb. ex Becc. & Song mật & Arecaceae & VU \\
\hline & Disporopsis longifolia Craib & Hoàng tinh cách & Convallariaceae & VU \\
\hline & Ophiopogon tonkinensis Rodr. & Xà bi bắc bộ & Convallariaceae & VU \\
\hline & Peliosanthes teta Andr. & Sâm cau & Convallariaceae & VU \\
\hline & Polygonatum kingianum Coll et Hemsl & Hoàng tinh vòng & Convallariaceae & $\mathrm{VN}$ \\
\hline & Dioscorea collettii Hook.f & Nần nghệ & Dioscoraceae & EN \\
\hline & Curculigo orchioides Gaertn. & Ngải cau & Hypoxidaceae & EN \\
\hline & Anoectochilus setaceus Blume & Lan kim tuyến & Orchidaceae & EN \\
\hline & Dendrobium chrysanthum Lindl. & Ngọc vạn vàng & Orchidaceae & EN \\
\hline & Smilax petelotii T. Koyama & Kim cang petelot & Smilacaceae & CR \\
\hline & Smilax poilanei Gagnep. & Kim cang poilane & Smilacaceae & $\mathrm{CR}$ \\
\hline & Smilax elegantissima Gagnep. & Kim cang tán không cuống & Smilacaceae & VU \\
\hline
\end{tabular}




\begin{tabular}{llll}
\hline Stemona cochinchinensis Lour. & Bách bộ nam & Stemonaceae & VU \\
Stemona pierrei Gagnep. & Bách bộ piere & Stemonaceae & VU \\
Stemona saxorum Gagnep. & Bách bộ đứng & Stemonaceae & VU \\
Tacca integrifolia Ker-Gawl. & Ngải rơm & Taccaceae & VU \\
Tacca subflabellata P.P. Ling \& C.T. Ting & Râu hùm việt & Taccaceae & VU \\
Paris polyphylla Smith & Trọng lâu nhiều lá & Triliaceae & EN \\
\hline
\end{tabular}

Kết quả cho thấy có 22 loài thực vật thuộc lớp Một lá mầm ở Khu BTTN Pù Hoạt được đề cập tới trong Sách Đỏ Việt Nam. Trong đó có 2 loài rất nguy cấp $(\mathrm{CR})$ là Kim cang petelot (Smilax petelotii $\mathrm{T}$. Koyama) và Kim cang poilane (Smilax poilanei Gagnep.); 6 loài nguy cấp $(\mathrm{EN})$ và 13 loài sẽ nguy cấp (VU) và 01 loài ít nguy cấp (LR). Những loài thực vật có giá trị làm thuốc, làm cảnh cho nên nó bị khai thác quá mức dẫn đến trong tự nhiên đang bị cạn kiệt dần và có nguy cơ tuyệt chủng. Vì vậy, chúng ta cần có những chính sách hợp lý làm giảm sự tác động đến môi trường sống để bảo vệ nguồn gen. Như vậy, nguồn gen thực vật bị đe dọa tuyệt chủng thuộc Một lá mầm ở Pù Hoat rất đa dạng và phong phú, thuộc nhiều nhóm khác nhau. Vì vậy, cần có những nghiên cứu chuyên sâu để làm cơ sở khoa học, bảo tồn và phát triển bền vững trong tương lai.
Các loài thực vật quý hiếm Một lá mầm ở Khu BTTN Pù Hoạt có đặc điểm là phần bố chủ yếu dưới tán rừng, là những cây thân thảo ưa ẩm. Cho nên, cần có những chính sách bảo tồn tại chỗ (In situ) như Lan kim tuyến (Anoectochilus setaceus Blume), Hoàng tinh cách (Disporopsis longifolia Craib), Thiên niên kiện lá to (Homalomena gigantea Engl.), Bách bộ piere (Stemona pierrei Gagnep.),...

\section{4. Đa dạng về yếu tố địa lý}

Đánh giá về yếu tố địa lý theo thang phân loại của Nguyễn Nghĩa Thìn (2007) [5]. Trong 432 loài thực vật Một lá mầm ở Pù Hoạt thì 424 loài đã được đánh giá còn 8 loài chưa đủ thông tin, kết quả được trình bày ở Bảng 4 .

Bảng 4. Yếu tố địa lý của các loài thực vật Một lá mầm ở Khu BTTN Pù Hoạt

\begin{tabular}{|c|c|c|c|c|c|}
\hline Ký hiệu & Các yếu tố địa lý & Số loài & $\begin{array}{ll}\text { Tỷ } & \text { lệ } \\
(\%)\end{array}$ & Số loài & Tỷ lệ (\%) \\
\hline 1 & Toàn thế giới & 1 & 0,23 & 1 & 0,23 \\
\hline 2 & Liên nhiệt đới & 17 & 3,94 & \multirow{3}{*}{$\begin{array}{l}\text { Liên nhiệt } \\
\text { đới }\end{array}$} & \multirow{4}{*}{6,02} \\
\hline 2.1 & Nhiệt đới châu Á, châu Úc, châu Mỹ & 2 & 0,46 & & \\
\hline 2.2 & Nhiệt đới châu Á, châu Phi và Châu Mỹ & 5 & 1,16 & & \\
\hline 2.3 & Nhiệt đới châu Á và Châu Mỹ & 2 & 0,46 & 26 & \\
\hline 3 & Cổ nhiệt đới & 5 & 1,16 & nhiệt & \\
\hline 3.1 & Nhiệt đới châu Á và châu Úc & 21 & 4,86 & đới & \multirow[t]{2}{*}{9,03} \\
\hline 3.2 & Nhiệt đới châu Á và châu Phi. & 13 & 3,01 & 39 & \\
\hline 4 & Nhiệt đới châu Á & 77 & 17,82 & \multirow{4}{*}{$\begin{array}{l}\text { Nhiệt, đới } \\
\text { châu Á }\end{array}$} & \multirow{6}{*}{49,31} \\
\hline 4.1 & Đông Dương - Malêzi & 35 & 8,10 & & \\
\hline 4.2 & Lục địa châu Á nhiệt đới & 46 & 10,65 & & \\
\hline 4.3 & Lục địa Đông Nam Á & 17 & 3,94 & & \\
\hline 4.4 & Đông Dương - Nam Trung Quốc & 21 & 4,86 & \multirow[t]{2}{*}{213} & \\
\hline 4.5 & Đông Dương & 17 & 3,94 & & \\
\hline 5 & Ôn đới Bắc & 1 & 0,23 & \multirow{2}{*}{ Ôn đới } & \multirow{2}{*}{6,94} \\
\hline 5.1 & Đông Á-Bắc Mỹ & 0 & 0,00 & & \\
\hline
\end{tabular}




\begin{tabular}{llllll}
\hline 5.2 & Ôn đới cổ thế giới & 1 & 0,23 & & \\
5.3 & Ôn đới Địa Trung Hải-Châu Âu-Châu Á & 3 & 0,69 & 30 & \\
5.4 & Đông Á & 25 & 5,79 & & \\
6 & Đặc hữu Việt Nam & 55 & 12,73 & Đặc hữu & 23,38 \\
6.1 & Cận đặc hữu Việt Nam & 46 & 10,65 & 101 & 3,24 \\
7 & Cây trồng & 14 & 3,24 & 14 & 1,85 \\
8 & Yếu tố chưa xác định & 8 & 1,85 & 8 & 100 \\
\hline & Tồng & 432 & 100 & 432 & 100 \\
\hline
\end{tabular}

Kết quả Bảng 4 cho thấy, trong các yếu tố địa lý trên thì yếu tố nhiệt đới chiếm tỷ lệ cao nhất $64,36 \%$, yếu tố đặc hữu và cận đặc hữu đứng thứ 2 chiếm $23,38 \%$, tiếp đến là yếu tố ôn đới chiếm $6,90 \%$; yếu tố cây trồng $3,24 \%$; yếu tố chưa xác định chiếm $1,85 \%$ và yếu tố toàn cầu $0,18 \%$. Xét trong mối quan hệ với các hệ thực vật chấu Á, thì lớp Một lá mầm Pù Hoạt có mối quan hệ với yếu tố Đông Dương-Ấn Độ (4.2) là gân nhất với $10,65 \%$; Đông DươngMalezi (4.1) với 8,10; tiếp theo là Đông DươngNam Trung Quốc (4.3) với 4.86\% và Đông Dương-Hymalaya và Đông Dương cùng chiếm $3,94 \%$.

\section{5. Đa dạng về dạng sống}

Dạng sống nói lên bản chất sinh thái của hệ thực vật cũng như các hệ sinh thái khác. Khi phân tích phổ dạng sống của lớp Một lá mầm ở Pù Hoạt, áp dụng có biến đổi hệ thống phân loại dạng sống của Raunkiaer (1934) [11] thuộc 6 nhóm là nhóm cây chồi trên $(\mathrm{Ph})$, nhóm cây chồi mặt đất $(\mathrm{Ch})$, nhóm cây chồi nửa ẩn $(\mathrm{Hm})$, nhóm cây chồi ẩn $(\mathrm{Cr})$, nhóm cây thân thảo (Th) và nhóm cây chồi thủy sinh (Bảng 5 ).

Bảng 5 . Số lượng và tỉ lệ \% các nhóm dạng sống ở Khu BTTN Pù Hoạt

\begin{tabular}{llll}
\hline $\begin{array}{l}\text { Ký } \\
\text { hiệu }\end{array}$ & Dạng sống & $\begin{array}{l}\text { Số } \\
\text { lượng }\end{array}$ & $\begin{array}{l}\text { Tỷ lệ } \\
\%\end{array}$ \\
\hline $\mathrm{Ph}$ & Cây chồi trên & 181 & 41,90 \\
$\mathrm{Ch}$ & Cây chồi sát đât & 107 & 24,77 \\
$\mathrm{Hm}$ & Cây chồi nửa ẩn & 36 & 8,33 \\
$\mathrm{Cr}$ & Cây chồi ẩn & 66 & 15,28 \\
$\mathrm{Th}$ & Cây chồi một năm & 37 & 8,56 \\
$\mathrm{Hy}$ & Cây chồi sống ở nước & 5 & 1,16 \\
\hline Tổng số loài & 432 & 100 \\
\hline
\end{tabular}

Bảng 5 cho thấy, nhóm cây chồi trên $(\mathrm{Ph})$ chiếm ưu thế với 181 loài chiếm $41,90 \%$ tổng số loài; nhóm cây chồi sát đất với 107 loài chiếm $24,77 \%$; nhóm cây chồi ẩn với 66 loài chiếm $15,28 \%$; nhóm cây chổi 1 năm với 37 loài chiếm $8,56 \%$; nhóm cây chồi nửa ẩn với 36 loài chiếm $8,33 \%$ và nhóm cây sống ở nước với 5 loài chiếm $1,16 \%$. Như vậy, trong lớp một lá mầm thì nhóm cây chồi trên $(\mathrm{Ph})$ chiếm tỷ lệ không đáng kể do dạng thân của các loài chủ yếu là thân thảo, thân bụi, chúng sống chủ yếu dưới tán rừng. Từ đó, lập phổ dạng sống của hệ thực vật nghiên cứu như sau: $\mathrm{SB}=41,90 \mathrm{Ph}+$ $24,77 \mathrm{Ch}+8,33 \mathrm{Hm}+15,28 \mathrm{Cr}+8,56 \mathrm{Th}+1,16 \mathrm{Hy}$.

\section{Kết luận}

Qua điều tra lớp Một lá mầm ở Khu BTTN Pù Hoạt, Nghệ An đã xác định được 432 loài, 173 chi và 37 họ; bổ sung 260 loài, 76 chi và 8 họ cho Danh lục thực vật Khu BTTN Pù Hoạt (2013).

Lớp Một lá mầm ở Pù Hoạt với 22 loài có nguy cơ bị tuyệt chủng được ghi trong Sách Đỏ Việt Nam (2007), 2 loài rất nguy cấp $(\mathrm{CR}), 6$ loài nguy cấp (EN), 13 loài sẽ nguy cấp (VU) và 1 loài ít nguy cấp (LR).

Có nhiều loài cây cho giá trị sử dụng, cây làm thuốc có số loài cao nhất 197 loài, cây làm cảnh 94 loài, cây ăn được 48 loài, cây cho tinh dầu 38 loài, cây cho thức ăn gia súc 35 loài, cây cho gia vị và cây đan lát cùng 12 loài, cây lấy gỗ 9 loài và cây cho sợi 8 loài.

Trong các yếu tố địa lý thì yếu tố nhiệt đới chiếm $64,36 \%$, yếu tố đặc hữu và cận đặc hữu đứng thứ 2 chiếm $23,38 \%$, yếu tố ôn đới chiếm 
$6,90 \%$; yếu tố cây trồng $3,24 \%$; yếu tố chưa xác định chiếm $1,85 \%$ và yếu tố toàn cầu $0,18 \%$.

Qua quá trình nghiên cứu đã lập phổ dạng sống của Lớp Một lá mầm Pù Hoat như sau: SB $=41,90 \mathrm{Ph}+24,77 \mathrm{Ch}+8,33 \mathrm{Hm}+15,28 \mathrm{Cr}+$ $8,56 \mathrm{Th}+1,16 \mathrm{Hy}$.

\section{Lời cảm ơn}

Các tác giả xin chân thành cảm ơn Sở Nông nghiệp và Phát triển Nông thôn Nghệ An đã tài trợ kinh phí để thực hiện đề tài này.

\section{Tài liệu tham khảo}

[1] Viện Điều tra Quy hoạch Rừng, Điều tra đa dạng sinh học Pù Hoạt làm cơ sở Thành lập Khu Bảo tồn Thiên nhiên, Vinh, 2013.

[2] Lê Thị Hương, Đỗ Ngọc Đài, Đa dạng thực vật và bảo tồn ở Khu Bảo tồn Thiên nhiên Pù Hoạt, Nghệ An, Tạp chí Khoa học và Công nghệ, 50 (2012) 1347-1352.

[3] Hoàng Danh Trung, Phạm Hồng Ban, Đỗ Ngọc Đài, Đa dạng thực vật bậc cao có mạch ở vùng đệm Khu bảo tồn thiền nhiên Pù Hoạt, Nghệ An, Tạp chí Nông nghiệp và Phát triển Nông thôn, 16 (2010) 90-94.

[4] Sở Khoa học và Công nghệ Nghệ An, Nghiên cứu đa dạng sinh học Khu Bảo tồn Thiên nhiên Pù Hoạt, Nghệ An đề xuất biện pháp bảo vệ, Vinh, 2016.

[5] Nguyễn Nghĩa Thìn, Các phương pháp nghiên cứu thực vật, NXB Đại học Quốc gia, Hà Nội, 2007.
[6] Nguyễn Tiến Bân, Cẩm nang tra cứu và nhận biết các họ thực vật hạt kín ở Việt Nam. NXB Khoa học và kỹ thuật, Hà Nội, 1997.

[7] Phạm Hoàng Hộ, Cây cỏ Việt Nam, Quyển III, NXB Trẻ, TP HCM, 2000.

[8] P. Wu, P. Raven (Eds.) et al., Flora of China, Beijing \& St. Louis. Vol. 1 (2002) 25.

[9] R.K. Brummitt, Vascular plant families and genera, Royal Botanic Gardens, Kew, 1992.

[10] Nguyễn Tiến Bân (Chủ biên) et al., Danh lục các loài Thực vật Việt Nam, Tập III, NXB Nông nghiệp, Hà Nội, 2005.

[11] C. Raunkiaer, Plant life forms, Claredon, Oxford, 1934.

[12] Nguyễn Tiến Bân (Chủ biên) et al., Sách Đỏ Việt Nam (Phần II: Thực vật). NXB. Khoa học tự nhiên và Công nghệ, Hà Nội, 2007.

[13] Ly Ngoc Sam, Dang Van Son, Do Dang Giap, Truong Ba Vuong, Do Ngoc Dai, Nguyen D. Hung, Zingiber nudicarpum D. Fang (Zingiberaceae) a new record for Vietnam, Bioscience Discovery, 8 (2017) 01-05.

[14] Nguyễn Thanh Nhàn, Nghiên cứu đa dạng thực vật VQG Pù Mát và đề xuất các giải pháp bảo tồn, Luận án Tiến sĩ Sinh học, Vinh, 2017.

[15] Đặng Quốc Vũ, Nghiên cứu tính đa dạng thực vật làm cơ sở cho công tác bảo tồn tại Khu Bảo tồn thiên nhiên Xuân Liên, Thanh Hóa, Luận án Tiến sĩ Sinh học, Hà Nội, 2016.

[16] Võ Văn Chi, Từ điển cây thuốc Việt Nam, Tập III. NXB Y học, Hà Nội, 2012.

[17] Triệu Văn Hùng (chủ biên), Lâm sản ngoài gỗ ở Việt Nam, NXB Bản đồ, Hà Nội, 2007. 